\title{
TURBINA DE RECUPERAÇÃO DE GÁS DE TOPO - TRT: UMA ALTERNATIVA VIÁVEL PARA GERAÇÃO DE ENERGIA ELÉTRICA EM PLANTAS SIDERÚRGICAS*
}

Joaquim Luiz Monteiro Barros ${ }^{1}$ Fabiana Moreira Costa

\section{Resumo}

Este trabalho tem como objetivo principal apresentar de forma didática e com um exemplo prático a viabilidade da instalação de turbinas TRT, com a finalidade de gerar energia elétrica em plantas siderúrgicas.

Palavras-chave: Turbina; TRT; Energia Elétrica.

\section{TRT TOP PRESSURE RECOVERY TURBINE: FEASIBLE ALTERNATIVE TO ELECTRICAL ENERGY GENERATION IN STEEL PLANTS}

\section{Abstract}

The purpose of this paper is to present in a didactic way and with practical examples, the feasibility of the installation of TRT turbines, with the objective of electrical energy generation in the steel plants.

Keywords: TRT; Turbine; Electrical Energy

1 Engenheiro Mecânico, Mestre em Economia com ênfase em Energia, Pós Graduado em Eficiência Energética, Diretor de Desenvolvimento de Negócios, Kuttner do Brasil, BH, MG, Brasil.

2 Engenheira de Energia, Estudante Engenharia Elétrica PUC-MG, Estagiária de Desenvolvimento de Negócios, Kuttner do Brasil, Belo Horizonte, MG, Brasil. 


\section{INTRODUÇÃO}

A possibilidade de geração de eletricidade através do aproveitamento energético no processo de produção de gusa / aço, sem o consumo adicional de combustível, pode ser um importante fator na melhoria da eficiência energética e no aumento da competitividade de uma planta siderúrgica.

O objetivo deste trabalho é demonstrar que a instalação de turbinas TRT, cuja tecnologia se encontra consolidada, pode-se gerar energia de forma contínua e confiável, reduzindo o custo energético da planta e/ou agregando uma receita adicional, com a exportação / venda da eletricidade gerada.

\section{MATERIAIS E MÉTODOS}

\subsection{Turbina de Recuperação de Gás de Topo - TRT}

A turbina de recuperação de gás de topo - TRT, é uma turbina de expansão que ao ser acoplada a um gerador, transforma a energia de pressão e cinética dos gases do Alto Forno em energia elétrica.

A TRT normalmente, é instalada após o sistema de limpeza do gás do Alto Forno e conforme já informado anteriormente, não requer nenhum combustível adicional em sua operação.

Dependendo da capacidade de produção do Alto Forno pode-se instalar uma ou mais turbinas TRT e se gerar algo como 30 ou $40 \mathrm{MW}$.

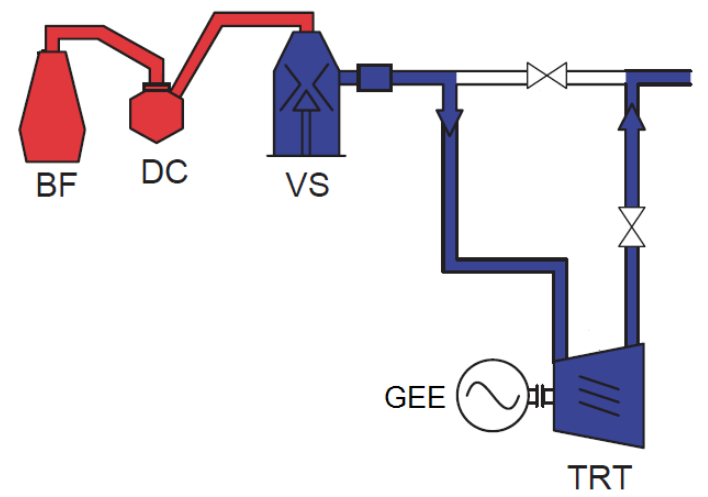

Figura 1. Fluxograma Esquemático da Instalação da TRT.

Onde:

- BF: Alto Forno;

- DC: Coletor de pó;

- VS: Coletor de pó tipo úmido;

- TRT: Turbina de recuperação de pressão de topo;

- GEE: Gerador de energia elétrica. 


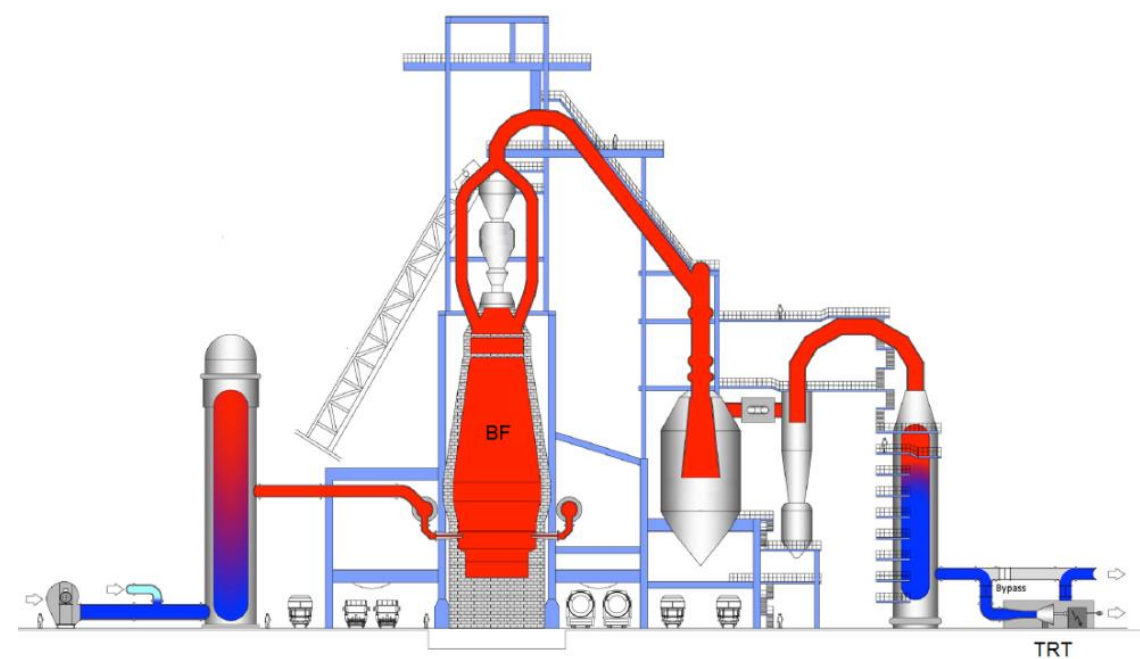

Figura 2. Desenho Esquemático da Instalação da TRT.

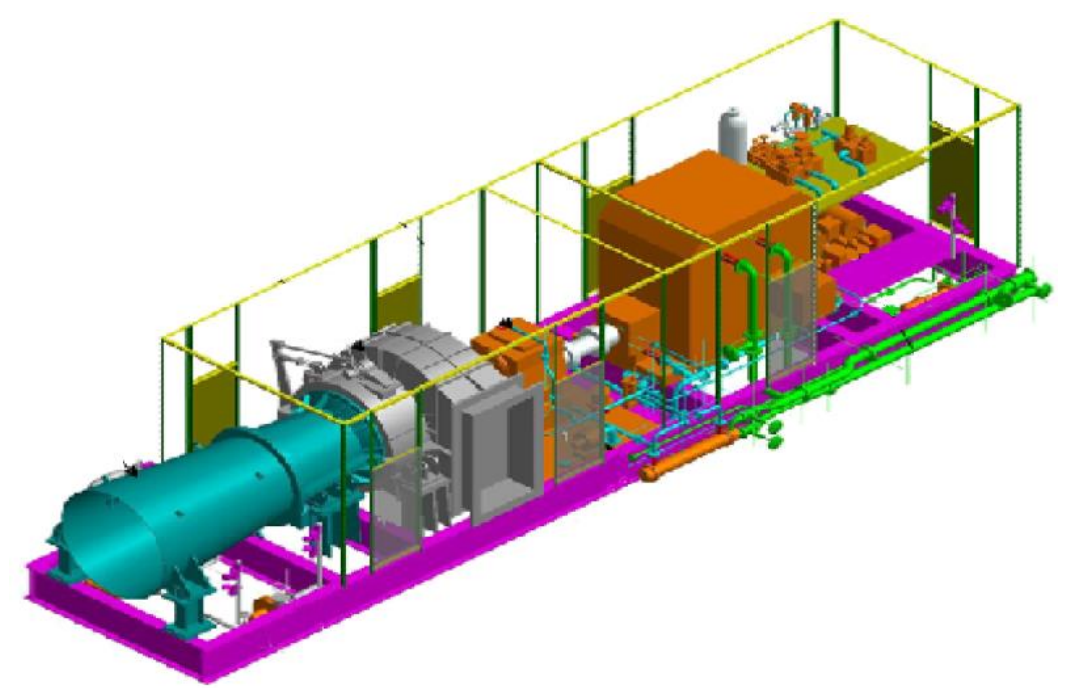

Figura 3. Desenho Esquemático do Conjunto TRT.

\section{RESULTADOS E DISCUSSÃO}

Segue abaixo o resumo de um estudo real para uma instalação existente no Brasil.

\subsection{Dados da Capacidade de Geração de Energia Elétrica}

Tabela 1. Dados da Capacidade de Geração de EE

\begin{tabular}{lcc}
\hline Itens & Unidade & Valor \\
\hline Potência & MW & 24,00 \\
\hline Garantia Física & MWmed & 18,26 \\
\hline GF Ajustada (CG) & MWmed & 17,80 \\
\hline Fator Capacidade Máx & $\%$ & 83 \\
\hline Fator Disponibilidade & $\%$ & 76,10 \\
\hline Perdas Transmissão & $\%$ & 2,50 \\
\hline
\end{tabular}


Com base nos dados acima, a instalação de TRT terá disponibilidade máxima de geração bruta de 160.000MWh/ano.

Como disponibilidade de energia exportável, já considerando as perdas de transmissão, tem-se $156.000 \mathrm{MWh}$ /ano como energia vendável.

\subsection{Dados / Premissas básicas}

- Vida útil da instalação: 10 anos (para efeito de cálculo econômico);

- Custo capital: $12 \%$ aa;

- Investimento necessário para instalação da turbina e todos os sistemas auxiliares necessários: $\mathrm{R} \$ 98.000 .000,00$;

- OPEX: $\mathrm{R} \$ 650.000,00 / \mathrm{ano}$

\subsection{Cálculo da Receita Anual da Energia Vendável (RAE)}

Considerando-se um valor líquido de $\frac{R \$ 219,00}{M W}$ para uma tarifa média de venda de energia, negociável no mercado, tem-se:

$R A E=$ Disponibilidade líquida de EE exportável $*$ tarifa líquida média de veda de EE (Equação 1)

$$
\begin{aligned}
& R A E=156.000 \frac{M W h}{a n o} * 219 \frac{R \$}{M W h} \\
& R A E=34.164 .000,00 \frac{R \$}{a n o}
\end{aligned}
$$

\subsection{Cálculo da Receita Líquida Anual (RLA)}

$$
\begin{aligned}
& R L A=34.164 .000-650.000 \\
& R L A=33.514 .000,00
\end{aligned}
$$

$$
R L A=R A E-O P E X \text { anual (Equação 2) }
$$

Desconsiderando o valor anual de OPEX, tem-se uma receita líquida anual de $R \$$ 33.514.000,00.

\subsection{Resumo do Estudo de Viabilidade Econômica}

\subsubsection{Cálculo do Valor Presente Líquido (VPL)}

$$
V P L=-I+\sum_{t=1}^{n} \frac{F C_{t}}{(1+K)^{t}} \quad \text { Equação } 3
$$


Onde:

- I = investimento;

- $F C=$ fluxo de caixa;

- $\mathrm{K}=$ Custo de capital;

- $\mathrm{t}=$ tempo;

- $\mathrm{n}=$ vida útil do empreendimento.

$V P L=R \$ 91.361 .575,00$

\subsubsection{Cálculo da Taxa Interna de Retorno (TIR)}

$$
I=-I+\sum_{t=1}^{n} \frac{F C_{t}}{(1+T I R)^{t}}
$$

Onde:

- $\mathrm{n}$ = vida útil do empreendimento;

- $F C=$ fluxo de caixa;

- $\mathrm{TIR}$ = taxa interna de retorno;

- $\mathrm{t}=$ tempo;

- $\mathrm{I}$ = investimento.

$\mathrm{TIR}=32: \%$

\subsubsection{Cálculo de Payback}

Payback $=3,8$ anos

\section{CONCLUSÃO}

A instalação de uma turbina de recuperação de gás de topo no Alto Forno de uma planta siderúrgica, com a finalidade de gerar energia elétrica para consumo próprio ou exportação (venda) pode ser uma alternativa viável tecnicamente e economicamente apesar de um payback relativamente longo para a realidade industrial brasileira. No entanto, em muitos casos, a TRT pode ser um fator importante na melhoria da eficiência e até mesmo, no aumento da competitividade da planta.

\section{REFERÊNCIAS}

$1 \quad$ Bartels von Varnbüler. Kuttner - TRT Study, Essen; 2014.

2 Barros Jr JLM. Integração de Utilidades, Recuperação de Calor e Cogeração em Sistemas de aquecimento de fluido térmico (pós-graduação). Rio de Janeiro: CEFET; 2002.

3 Buarque, Cristovan. Avaliação Econômica de Projetos. $7^{\text {a }}$ edição. Rio de Janeiro: Campus, 1984.

4 Barros Jr JLM. Geração de Energia Elétrica (Mestrado). Rio de Janeiro; 2009.

5 Brasil Energia n 437, "Indicadores" - edição Brasil Energia; 2017. 